\title{
Clinical Implications of Social Communication Disorder
}

\author{
Suk-Ho Shin \\ Dr. Shin's Child and Adolescent Psychiatric Clinic, Seoul, Korea
}

\section{사회적 의사소통장애의 임상적 이해}

\author{
신 석 호 \\ 신석호 소아청소년 정신과
}

\begin{abstract}
Social (pragmatic) communication disorder (SCD) is a new diagnosis included under communication disorders in the neurodevelopmental disorders section of Diagnostic and Statistical Manual of Mental Disorders-5. SCD is defined as a primary deficit in the social use of nonverbal and verbal communication. SCD has very much in common with pragmatic language impairment, which is characterized by difficulties in understanding and using language in context and following the social rules of language, despite relative strengths in word knowledge and grammar. SCD and Autism Spectrum Disorder (ASD) are similar in that they both involve deficits in social communication skills, however individuals with SCD do not demonstrate restricted interests, repetitive behaviors, insistence on sameness, or sensory abnormalities. It is essential to rule out a diagnosis of ASD by verifying the lack of these additional symptoms, current or past. The criteria for SCD are qualitatively different from those of ASD and are not equivalent to those of mild ASD. It is clinically important that SCD should be differentiated from high-functioning ASD (such as Asperger syndrome) and nonverbal learning disabilities. The ultimate goals are the refinement of the conceptualization, development and validation of assessment tools and interventions, and obtaining a comprehensive understanding of the shared and unique etiologic factors for SCD in relation to those of other neurodevelopmental disorders.
\end{abstract}

Key Words: Social communication disorder; Pragmatic language impairment; Autism spectrum disorder.

Received: May 1, 2017 / Revision: June 9, 2017 / Accepted: August 10, 2017

Address for correspondence: Suk-Ho Shin, Dr. Shin's Child and Adolescent Psychiatric Clinic, 651 Gaepo-ro, Gangnam-gu, Seoul 06335, Korea Tel: +82-2-2226-2231, Fax: +82-2-2226-2232, E-mail: leeshin@netsgo.com

\section{서 론}

2013년 5월에 발간된 Diagnostic and Statistical Manual of Mental Disorders(DSM) $-5^{1)}$ 에 새로이 포함된 진단기준인 사 회적 의사소통장애(social communication disorder)는 아동/ 청소년이 자폐스펙트럼장애의 진단기준에 해당이 안 되면서, 기본적인 어휘나 문장구성 능력이 별로 떨어지지 않지만, 화 용언어에 심각하게 문제가 있어 대인관계나 사회성에 어려움 이 발생하는 경우에 진단이 내려진다.

최근 우리나라에서도 사회적 의사소통장애의 진단이 아동 에게 내려지고 있으나, 아직까지는 참고문헌이 충분하지 않고, 임상적으로도 경험이 부족하여 실제의 임상에서 정확한 진단 등이 제대로 이루어지지 못하고 있는 실정이다. 또한 사회적 의사소통장애라는 질환 자체가 아직도 논란의 여지가 있는

This is an Open Access article distributed under the terms of the Creative Commons Attribution Non-Commercial License (http://creativecommons.org/licenses/by-nc/4.0) which permits unrestricted non-commercial use, distribution, and reproduction in any medium, provided the original work is properly cited.
부분이 많아서 보다 지속적인 연구가 필요하다고 하겠다.

본 종설의 목적은 사회적 의사소통장애의 진단기준에 대 하여 살펴보고, 사회적 의사소통장애의 진단에서 논란이 되 고 있는 부분들 및 임상적 의의에 대하여 고찰하고자 한다.

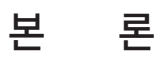

DSM-5에서는 사회적 의사소통장애에 대하여 두 군데에서 표현되는데, '사회적 의사소통장애'의 진단기준과 자폐스펙트 럼장애의 주(note)에서 언급하고 있다. 진단에 대하여 상당히 다른 개념을 포함하고 있는 두 가지의 기준으로 볼 수 있으며, 이러한 차이는 사회적 의사소통장애에 대한 이해를 혼돈스럽 게 하고 있다.

\section{사회적 의사소통장애의 임상 특성}

최근에는 아동이 보이는 언어상의 문제점에 대하여 의사소 통능력과 관련하여 화용언어에 관심이 집중되고 있다. 화용언 
어(pragmatic language)는 의사소통능력과 관련이 있으며, 이 는 원하는 것을 다른 사람이 알도록 만들고, 사건에 대하여 다 른 사람에게 애기를 하며, 행위에 대하여 설명을 할 수 있고 다 른 사람의 존재나 의미를 인식하는 능력을 말한다. ${ }^{2)}$ 사회적 맥 락 안에서 아동이 전하고자 하는 의미를 의사소통할 수 있는 기술이나 상대방의 의도를 파악하는 능력이 얼마나 떨어지느 냐가 중요하다고 여겨진다. 아동들이 말을 하게 되었다고 해 서, 반드시 적절한 의사소통을 한다고 말할 수는 없다. 이들이 언어사용의 규칙을 획득하더라도 자신이 습득한 언어를 사회 적 맥락에서 일반화시키지 못하는 경우가 대부분이다. 언어사 용의 규칙을 배운 것만으로는 연령에 맞는 적절한 의사소통 능력을 익혔다고 할 수 없다. 상대방과의 의사소통은 단순히 말할 수 있거나 적절한 순서로 단어를 조합할 수 있는 그 이상 이다.

일반적으로 부모들은 아동의 언어 발달이 이상하다는 느낌 으로부터 아동의 발달에 대하여 염려하기 시작한다. 부모들이 말이 늦는다고 걱정을 해서 병원에 오는 시기는 대체로 만 2 3 세 정도부터이다. 때로는 아동이 알아듣기는 잘 알아듣는 것 같은데 전혀 말을 못하거나 말을 하여도 꼭 필요한 단어를 표 현하지 못하기도 한다. 혹시 혀가 짧은 것은 아닌지, 또는 머리 가 나쁜 것은 아닌지 문의를 해오는 경우가 많다. 실제적으로 아동이 만 2세 정도까지 의미있는 단어를 상황에 적절하게 말 하지 못하는 등, 필요한 표현 언어능력을 보이지 못하거나, 만 1 세가 넘은 아동이 비언어적인 의사소통기술(예를 들어, 몸짓, 눈짓, 얼굴표정, 미소 등)에서 비교적 적절한 발달이 없어 상호 소통이 안된다면, 반드시 소아정신과를 방문하여 평가를 받아 야 한다. ${ }^{3)}$

사회적 의사소통장애로 진단된 아동들이 보이는 의사소통 의 양상은 다음과 같다. 같은 반 아동들과 대화를 주거니 받거 니 하면서 상호적으로 대화를 개시하고 유지하다가 끝내거나 또는 대화의 주제를 $\mathrm{A}$ 에서 $\mathrm{B}$ 로 바꾸는 능력이 부족하다. 자신 의 생각이나, 경험, 주제 등에 대하여 구체적으로 길게 설명하 는 능력이 많이 떨어진다. 간단한 표현이나 짧은 문장을 사용 하여 생각을 말로 기술할 수 있으나, 말해야 하는 문장이 길 어지면 아동은 당황해 하거나 말을 제대로 끝맺지 못할 수 있 다. 아동이 어떠한 상황에 처했을 때 언어를 사용하여 문제를 해결하는 능력이 부족한 것이 특징이다. 이러한 상황에서 어쩔 줄 몰라 하면서 부모나 주변의 도움을 청하는 모습은 애처롭 기까지 하다. 의사소통기술의 부족은 아동으로 하여금 친구들 을 사귀는 것을 힘들게 한다. 사회적 의사소통장애를 보이는 아동들 중 일부는 수업시간에 답변을 한다든지, 또는 친구들 과 애기를 하면서 어울리는 것을 회피하게 한다. 결과적으로 아동들은 심리적으로 위축된 양상을 보이면서 자신감의 부족
및 자존감의 저하를 나타내는 경우가 흔하다. ${ }^{2)}$

사회적 의사소통장애를 정확하게 이해하기 위하여 유사한 발 달 문제들과 감별진단을 하는 것이 중요하다. 사회적 의사소통 장애는, 지능이나 기본적인 언어발달은 정상범주에 해당하면 서 화용언어의 저하를 보인다는 점에서 과거에 언어치료학계 에서 화용언어장애(pragmatic language impairment)로 진단 을 내리던 경우와 매우 유사하다고 할 수 있다. 연구자들은 화 용언어장애와 자폐스펙트럼장애를 구별하는 것에 대한 필요 성을 고려하였고, ${ }^{3}$ 화용언어장애는 자폐스펙트럼장애와 구분 된다는 연구결과들-7)이 있었다. 이 연구결과들은 화용언어장 애로 진단된 아동이 자폐스펙트럼장애 아동과 비교하여 자폐 스펙트럼장애의 주요 특징인 또래 관계 혹은 흥미 영역에 제 한을 보이지 않는다고 보고하였으며 화용언어장애에 자폐증 을 진단하는 데 중요한 의사소통, 사회적 상호작용, 관심과 흥 미 영역의 세 가지 문제가 항상 나타나는 것은 아니라고 하였다. 자폐스펙트럼장애 아동은 부적절한 억양과 톤이 동반된 집착 언어를 사용한 반면 화용언어장애 아동은 언어적 의사소통이 어려웠으나 비언어적 의사소통기술은 적절한 특성을 보였으 며,") 자폐아동에게서 보이는 또래관계 혹은 제한된 관심이나 흥미 측면에서 어려움을 갖지 않는다고 하였다. 한편, 사회적 의사소통장애와 화용언어장애는 증상적으로 매우 유사하지 만, 일부 차이점은 사회적 의사소통장애는 언어적 의사소통기 술은 공통적으로 떨어지면서 비언어적 의사소통기술이 어느 정도 떨어질 수 있지만, 화용언어장애는 언어적 의사소통기술 만 떨어지는 것으로 보고하고 있다. ${ }^{8)}$ 따라서 화용언어장애는 수용언어 및 표현언어는 별로 떨어지지 않으면서 화용언어에 뚜렷한 어려움을 보이는 경우로, 아동이 보이는 전반적인 발 달 및 기능수준의 장애는 경미하다고 할 수 있다.

사회적 의사소통장애로 진단되는 경우는 크게 두 가지로 나 누어 볼 수 있다. 처음 클리닉으로 내원할 때부터 아동의 언어 발달의 정도가 심각하지 않아 언어평가에서 수용언어와 표현 언어가 정상범주이지만 화용언어가 떨어지면서 사회성이 부족 한 사례들에 해당한다. 다른 경우들은 어려서 언어장애로 진 단되어 치료를 꾸준하게 받아 왔으나, 충분하게 증상이 치료되 지 못하고 화용언어의 문제가 남아 사회적 의사소통 장애로 진행되며, 후자의 경우들이 대부분이다. 어려서 언어발달이 늦 었음에도 불구하고, 소아정신과에서의 진료나 언어치료 등을 전혀 받지 않은 상태로 지내다가 초등학교에 입학 후 타 아동 들과의 차이를 알게 되어 뒤늦게 병원을 찾는 경우들도 종종 있다.

초등학교 1 학년인 영수는 언어 발달의 지연으로 1 년 전 초등 학교 입학을 유예한 바 있어 현재 9 살이다. 만 3 세 반 경에 영 수의 언어 발달이 늦는 것을 염려한 부모는 소아정신과를 방 
문하여, 언어발달이 지체되어 있으니 언어치료를 받고 어린이 집이나 유치원을 다니라는 치료적 권고를 들었다. 그러나, 자 폐증은 아니라는 소아정신과 의사의 말에 일단 안심을 한 부 모는 전문적인 치료없이 그냥 유치원에 다니면서 상태의 호전 을 기다려 보기로 결정하였다. 그러나, 영수가 나이는 들어가 지만, 또래의 아동들에 비하여 언어능력이나 사회성 발달이 많이 떨어진다고 생각한 부모는 만 5세가 지나 본 병원에 방 문하였다. 처음 진료가 의뢰되었을 때, 영수는 문장으로 의사 소통하는 능력이 뚜렷하게 떨어졌으며, 유치원에서 친구를 사 귀지 못하고 아이들과 어울리지 못하여 주변을 맴돌면서 유 치원의 프로그램에 잘 적응하지 못하는 모습을 보였고, 검사 결과 자신의 생활연령에 비하여 언어 발달연령이 2년 이상 떨 어지는 소견을 나타냈다. 언어치료와 인지치료를 받기 시작한 영수는 언어능력이나 인지기능의 객관적인 향상에도 불구하 고, 유치원에서 적응이 힘들다는 점을 지속적으로 호소하였 다. 영수의 심리적인 위축과 정서적인 문제를 도와주기 위하 여 개별 놀이치료를 시작하였으며, 또래 아동들과의 사회성 기 술 발달을 위하여 또래 놀이치료(사회성 그룹)를 추가적으로 시행하였다. 언어발달의 지연 및 사회성 부족 등에 대한 전문 적인 치료가 상대적으로 늦었던 영수의 경우, 부모는 적극적 인 치료를 통하여 증상을 호전시킨 후에 영수를 초등학교에 보내기로 하고 초등학교 입학 유예를 하였다. 초등학교에 입 학할 즈음, 언어검사에서 언어발달연령이 정상범주에 해당하 였으나 화용언어는 떨어지면서 가까운 친구를 사귀고 학우들 과 어울리는 것을 힘들어하여 여전히 전문적인 도움을 필요 로 하는 상태이다.

어려서 언어장애로 진단된 아동들이 치료시기를 놓치거나 또 는 치료가 충분히 시행되지 못하는 경우들은 학령기에 이르러 아동의 진단이 사회적 의사소통장애에 해당될 가능성이 있다.

\section{사회적 의사소통장애와 자폐스펙트럼장애의 차이점}

$\mathrm{DSM}-5^{1)}$ 자폐스펙트럼장애의 진단기준에서 추가적인 제안 으로, 사회적 의사소통에 뚜렷한 장해를 보이지만 자폐스펙 트럼장애의 진단기준에 맞지 않는 경우들은 사회적 의사소통 장애로 진단을 내리도록 명시하고 있다. 자폐스펙트럼장애의 진단기준에서 사회적 의사소통과 사회적 상호작용은 장애를 보이지만, 제한적이고 반복적인 패턴의 행위와 관심 또는 활 동에 해당하는 자폐 증상들이 없는 경우에 해당한다. 이 경 우에 해당하는 아동들의 기능수준이나 임상양상은 자폐스펙 트럼장애의 경우처럼 심각한 장애를 보이는 경우들도 포함될 가능성이 높다. 이러한 경우에 해당하는 아동들은 응용행동 분석(applied behavioral analysis) 조기치료 프로그램과 같이 자폐스펙트럼장애를 위한 치료들을 집중적으로 받도록 권고
하고 있다. ${ }^{9)}$

\section{〈DSM-5 자폐스펙트럼장애 진단기준 중 일부〉}

주(note): DSM-4에서 아스퍼거 장애와 비전형적 발달장애

(Pervasive Developmental Disorder-Not Otherwise Specified, PDD-NOS)로 확진된 경우들은 자폐스펙트럼장애의 진단이 내 려져야 한다. 사회적 의사소통 영역에서의 결함은 뚜렷하지만, 자폐스펙트럼장애의 진단기준에 부합하지 않는다면, 사회적 의 사소통장애로 진단을 내려야 한다.

자폐스펙트럼장애는 사회적 의사소통장애와 비교하여 사회 적 의사소통 영역에서의 어려움은 유사하지만, 과도한 관심을 가지면서 다른 관심영역으로의 유도가 여의치 않고, 지속적 으로 하려는 의도나 경향이 뚜렷하며, 대부분 나이가 들어서 도 비현실적으로 특이한 주제나 대상에 심한 집착을 지속적 으로 보여, 대상 아동의 일상적인 생활의 리듬을 깨뜨려 부정 적인 영향을 미치는 경우가 많다. 또한 자폐스펙트럼장애는 다 양한 상동증으로 손가락을 흔들기, 손을 퍼덕대기, 몸체를 앞 뒤나 좌우로 움직이기(finger flickering, hand flapping, body rocking, and body waving) 등을 보이거나, 운동 기획능력 (motor planning)에 문제가 있어 몸이 흐느적거리는 양상들을 나타내는 경우가 있지만, DSM-5 자폐스펙트럼장애의 진단기 준 중 주에 의하면, 사회적 의사소통장애는 운동성 매너리즘 이나 상동증이 발견되지 않아야 한다. ${ }^{10)}$

\section{사회적 의사소통장애의 감별진단}

DSM-5가 출간되기 이전 미국에서는 아스퍼거 증후군으로 진단되기 위하여 자폐적인 특성이 뚜렷하면서 전형적인 임상 적인 양상을 보여야 한다고 주장하였으나, 유럽에서는 아스퍼 거 증후군의 범주를 표현형(phenotype)으로 매우 포괄적으 로 보아, 자폐적인 특성이 뚜렷한 경우는 물론이고, 자폐적인 특성이 별로 없으면서 특이한 영역이나 대상에 관심이 많으 며, 대인관계에 서투른 양상을 보이면서 평생 동안의 엉뚱함 (lifelong eccentricity)을 개인의 특징으로 하는 대상들에게도 아스퍼거 증후군 또는 아스퍼거 성향이라는 표현을 사용하였 다. 유럽의 연구자들이 아스퍼거 증후군에 대하여 쓴 논문이 나 글들을 보면, 진단기준에는 정확하게 맞지는 않지만, 특이 한 영역이나 대상에 관심이 많으며, 대인관계에 서투른 양상 을 보이면서 평생 동안의 엉뚱함(lifelong eccentricity)을 개인 의 특징으로 하는 대상들에게 'Asperger trait', 'neurotypical people, 'latent Asperger syndrome' 등의 표현을 사용하였다. ${ }^{11)}$

아스퍼거 증후군과 유사하지만, 상대적으로 경미하면서 비 전형적인 양상을 보이는 증례들을 대상으로 엄격한 진단과정 
을 시행한다면, 그중 일부는 아스퍼거 증후군의 진단에 부합 되어 재진단되는 경우도 있을 것이다. 그러나 아스퍼거 증후군 의 진단기준에 맞지 않으면서, 상대적으로 경미한 여타의 증 례들에게 지능검사를 포함한 신경심리검사를 시행하여 세밀 한 진단을 내리게 되면, 사회적 의사소통장애 또는 비언어성 학습장애의 진단이 주어지는 경우가 상당수일 것이다.

사회적 의사소통장애와 아스퍼거 증후군의 구분은 임상적 으로 매우 중요하다. 아스퍼거 증후군이나 사회적 의사소통장 애는 친구를 새로이 사귀거나 유지하기가 어려우며, 상황에 부적절한 말을 언급하거나, 또는 상대방의 입장을 고려하지 않고 간섭을 하거나 말 참견을 하고, 사회적 맥락에서 상황을 연결하여 파악하고 인과관계를 이해하여 결과를 예견하는 상황 판단력이 떨어져서 사회적 관계형성능력이 떨어지는 증 상들을 공통적으로 보이고 있다. 사회적 의사소통장애는 또래 의 정상군에 비하여 대화의 맥락에 충분히 참여하지 못하고 화용언어(pragmatic language)가 미숙한 것이 특징이고, 또래 의 정상군에 비하여 눈맞춤이 어색하게 느껴지지만, 약 45 분 동안 시행하는 진료시간 동안 아동과 상당히 정서적인 교감 이 이루어진다고 확인할 수 있다. 하지만, 아스퍼거 증후군은 대화 상황에서 상호적인 면이 결여되고, 의도적인 의사소통이 자연스럽게 안 되며, 특정 사건에 대하여 언급하거나 마음의 상태에 대하여 이야기체로 자연스럽게 말하는 데 어려움이 있 다. 상대방의 관심사에 귀 기울이지 못하고 일방적인 대화를 하게 되어 보다 심각한 의사소통의 어려움을 겪는다. 특히, 소 아정신과 의사가 아스퍼거 아동과 진료 상담하는 동안 자연스 러운 눈맞춤이나 감정의 표현 및 정서적인 교감이나 감정의 상호적인 교류가 제대로 이루어지지 않는 등 비언어적 의사소 통기술이 부적절함을 파악할 수 있다. ${ }^{12}$

사회적 의사소통장애와 비언어성 학습장애는 임상적으로 유사점과 차이점이 있다. 유사점은 두 문제 모두 자폐스펙트럼 장애의 진단기준에 해당하지 않는다는 것이며, 또한 고기능 에 해당하며 사회성이 공통적으로 떨어진다. 차이점은 사회 적 의사소통장애의 핵심병리는 상호적인 의사소통의 부족으 로 인하여 발생하는 화용언어의 저하이며, 비언어성 학습장애 의 핵심병리는 우뇌기능의 저하에 따른 시지각 발달의 어려움 으로 볼 수 있다.13)

우리나라에서도 DSM-5 진단기준이 출간되기 전까지는 유 럽의 포괄적인 관점을 받아 들여, 자폐적인 특성은 별로 없으 면서 사회성이 부족하고 특이한 관심을 보이며, 종종 운동신 경은 떨어지고, 불안증상이나 틱 증상을 동반하기도 하는 경 우를 아스퍼거 증후군 내지는 아스퍼거 성향이라고 진단을 내 리곤 하였다. 이러한 관점에 대하여 상당수의 성인들이 동의하 여, 결과적으로 자신이 아스퍼거 증후군이라고 생각하는 경
우들이 많아졌다. 이러한 주장의 이론적 근거로 Christopher Gillberg의 책 ${ }^{\circledR A}$ guide to Asperger syndrome ${ }^{14)}$ 이 자주 인 용되었다. 하지만, 자폐적인 특성은 뚜렷하지 않으면서, 사회성 이 부족하고 특이한 관심을 보이는 경우에도 아스퍼거 증후군 내지는 아스퍼거 성향이라고 진단을 내린다는 주장은 Gillberg의 책에서만 언급되었고, Gillberg의 논문에서는 논의되 지 않았다. 사실상 이러한 주장은 DSM-5에서는 인정되지 못 한다. 자폐적인 특성이 별로 없어도 유사한 증상이 있으면 포 괄적으로 아스퍼거 증후군으로 진단한다는 주장은, 아스퍼거 증후군이 고기능 자폐스펙트럼장애에 포함된다는 DSM-5의 자폐스펙트럼장애 진단의 취지에 심각하게 어긋나는 것으로 볼 수 있다.

\section{DSM-IV-TR와 DSM-5에서 자폐스펙트럼장애의 진단적 변화}

$\mathrm{Kim}$ 등 $^{16)}$ 은 과거의 $\mathrm{DSM}-\mathrm{IV}^{-\mathrm{TR}^{15)}}$ 진단기준으로 전반적 발달장애의 진단을 받았던 환자들을 대상으로 $\mathrm{DSM}-5^{11}$ 자폐 스펙트럼장애의 진단기준을 적용하였을 때, 진단 변화에 대 한 연구를 시행하여 다음과 같은 결과를 얻었다.

1) DSM-IV-TR에서 전형적인 자폐증을 의미하는 자폐성 장 애(autistic disorder)의 경우는 DSM-5에서도 거의 다 자폐스 펙트럼장애의 진단기준에 해당되었다.

2) DSM-IV-TR에서 아스퍼거 증후군의 경우는 DSM-5에서 약 $90 \%$ 의 경우에만 자폐스펙트럼장애의 진단기준에 해당되었 으며, 그 외에는 사회적 의사소통장애의 진단이 주로 내려졌다.

3) DSM-IV-TR에서 비전형적인 자폐증을 의미하는 PDD$\mathrm{NOS}$ 의 경우는 DSM-5에서 약 70\%가 자폐스펙트럼장애의 진 단기준에 해당되었으며, 아닌 경우의 상당수가 사회적 의사소 통장애의 진단이 내려졌다. 따라서 과거에 PDD-NOS로 진단 되었던 환자들은 DSM-5 자폐스펙트럼장애 진단기준에 따라 재진단을 받을 필요가 있다.

Foley-Nicpon 등이는 DSM-IV-TR 기준 ${ }^{15)}$ 으로 자폐증으로 진단된 아동 및 청소년 45명을 대상으로 Autism Diagnostic Interview-Revised(ADI-R)와 Autism Diagnostic Observation Schedule(ADOS)의 검사항목들을 이용하여 DSM-5 기 준으로 자폐스펙트럼장애와 사회적 의사소통장애의 진단이 적절한지에 대하여 연구를 시행하였다. $\mathrm{ADOS}$ 만으로 진단을 시행할 때, $38 \%$ 만이 DSM-5 자폐스펙트럼장애의 진단기준에 맞았다. ADOS와 ADI-R를 함께 시행했을 때, DSM-IV-TR 적용 시 자폐증으로 진단된 대상들은 $100 \%$ 모두 DSM-5 자폐 스펙트럼장애 진단기준에 맞았다. 하지만, $\mathrm{ADOS}$ 의 검사항목 들이 사회적 의사소통장애를 진단하는 것에 부족하다고 주장 하였다.

DSM-IV-TR에서는 자폐성향이 있어 보이는 환자가 전형적 
인 자폐성 장애(autistic disorder)의 진단기준에 맞지 않으면, 비전형적 자폐증에 해당하는 상세불명의 전반적 발달장애 (PDD-NOS)의 진단이 내려졌었다. 하지만, DSM-5에서는 자 폐성향이 있어 보이지만 자폐스펙트럼장애의 진단기준에 정 확하게 맞지는 않는 경우들은 사회적 의사소통장애로 진단 을 내리도록 되어 있다.

과거에 우리나라에서는 전형적인 아스퍼거 증후군에 해당 되지 않으면서, 사회적 관계형성에서의 어색함과 협소하고 경 직된 사고, 지속적으로 특이하거나 엉뚱함을 보이는 대상들 에게 아스퍼거 성향이라고 하여 광범위하게 아스퍼거 증후군 진단이 적용되어 부적절하게 내려지던 시기가 있었다. 특히, 인터넷 검색을 통하여 정보를 보고 자신이 성인기 아스퍼거 증후군이라고 생각하는 경우들이 많다. ${ }^{12)}$ 따라서, 우리나라에 서는 DSM-IV-TR 기준으로 아스퍼거 증후군(장애)으로 진단 되었던 대상들 중 DSM-5 자폐스펙트럼장애 진단기준에 해당 되지 않아서 사회적 의사소통장애의 진단이 내려지는 경우들 이 미국의 결과보다 훨씬 높으리라 생각한다.

본 종설의 의의는 사회적 의사소통장애의 임상적인 의미 및 진단에서 보이는 어려움에 대하여 국내 최초로 문헌 고찰을 통하여 체계적인 정리를 시도하였다는 점이라 하겠다. 그럼에 도 불구하고 몇 가지의 제한점이 있는데, 첫째, 사회적 의사소 통장애를 이해함에 있어 필자는 다양한 임상적인 의미를 설 명하고자 하였으나, 진단에서 어려움을 명확하게 규명하는 데 일부 한계를 보였으며, 둘째, 사회적 의사소통장애는 현실 적으로 임상적인 진단이 이루어지는 경우가 대부분인지라, 임 상적으로 내려진 진단을 평가도구를 통하여 검증하기에 어려 움이 있고, 셋째, 사회적 의사소통장애와 아스퍼거 증후군 및 비언어성 학습장애를 감별하려는 노력은 소아정신과 영역에 서 초보적인 단계라 할 수 있어 보다 다양한 문헌고찰이 이루 어지지 못한 점을 들 수 있다. ${ }^{17,18)}$

\section{결 론}

사회적 의사소통장애의 진단 시 예상되는 어려움을 극복하 기 위해서는 임상적 면담을 통하여 자세하게 획득된 발달력 에 대한 정보와 함께 사회적 의사소통장애의 진단기준을 적 합하게 사용하려는 노력이 중요하다고 하겠다. 또한, 사회적 의 사소통장애의 유병률을 낮추기 위하여 언어장애로 진단된 아 동들이 어려서부터 충분한 시간을 투자하여 체계적인 치료를 받는 환경이 중요하다.

중심 단어: 사회적 의사소통장애; 자폐스펙트럼장애;

화용언어장애.

\section{Conflicts of Interest}

The author has no financial conflicts of interest.

\section{REFERENCES}

1) American Psychiatric Association. Diagnostic and Statistical Manual of Mental Disorders: DSM-5. 5th ed. Washington, DC: American Psychiatric Association;2013.

2) Bishop DVM. Pragmatic language impairment: a correlate of SLI, a distinct subgroup, or part of the autistic continuum? In: Bishop DVM, Leonard LB, editors. Speech language impairments in children: causes, characteristics, intervention and outcome. New York, NY: Psychology Press;2000.

3) Yang MB, Shin SH. Autism Spectrum Disorder A to Z. 2nd ed. Seoul: Sigmapress;2016.

4) Adams C. Clinical diagnostic and intervention studies of children with semantic-pragmatic language disorder. Int J Lang Commun Disord 2001;36:289-305.

5) Bishop DV, Norbury CF. Exploring the borderlands of autistic disorder and specific language impairment: a study using standardised diagnostic instruments. J Child Psychol Psychiatry 2002;43:917-929.

6) Conti-Ramsden G, Simkin Z, Botting N. The prevalence of autistic spectrum disorders in adolescents with a history of specific language impairment (SLI). J Child Psychol Psychiatry 2006;47:621628.

7) Jin YS, Pae S. Communication profiles of school-aged children with social communication disorder and high-functioning autism. Commun Sci Disord 2014;19:45-59.

8) Swineford LB, Thurm A, Baird G, Wetherby AM, Swedo S. Social (pragmatic) communication disorder: a research review of this new DSM-5 diagnostic category. J Neurodev Disord 2014;6:41.

9) Interagency Autism Coordinating Committee. IACC statement regarding scientific, practice and policy implications of changes in the diagnostic criteria for autism spectrum disorder. Washington, DC:IACC;2014.

10) Foley-Nicpon M, L Fosenburg S, G Wurster K, Assouline SG. Identifying high ability children with DSM-5 autism spectrum or social communication disorder: performance on autism diagnostic instruments. J Autism Dev Disord 2017;47:460-471.

11) Mattila ML, Kielinen M, Jussila K, Linna SL, Bloigu R, Ebeling H, et al. An epidemiological and diagnostic study of Asperger syndrome according to four sets of diagnostic criteria. J Am Acad Child Adolesc Psychiatry 2007;46:636-646.

12) Shin SH. Confusions and controversies about Asperger syndrome. J Korean Neuropsychiatr Assoc 2008;47:230-238.

13) Shin SH. Nonverbal learning disabilities and Asperger syndrome. 2nd ed. Seoul: Sigmapress;2016.

14) Gillberg C. A guide to Asperger syndrome. Cambridge: Cambridge University Press;2002.

15) American Psychiatric Association. Diagnostic and Statistical Manual of Mental Disorders: DSM-IV-TR. 4th ed. Text revision. Washington, DC: American Psychiatric Association;2000.

16) Kim YS, Fombonne E, Koh YJ, Kim SJ, Cheon KA, Leventhal BL. A comparison of DSM-IV pervasive developmental disorder and DSM-5 autism spectrum disorder prevalence in an epidemiologic sample. J Am Acad Child Adolesc Psychiatry 2014;53:500-508.

17) Fitzgerald M, Corvin A. Diagnosis and differential diagnosis of Asperger syndrome. Adv Psychiatr Treat 2001;7:310-318.

18) Gavilán B, Fournier-Del Castillo C, Bernabeu-Verdú J. Differences between the neuropsychological profiles of Asperger's syndrome and non-verbal learning disorder. Rev Neurol 2007;45:713-719. 